\title{
The Role of Justification in the Ordinary Concept of Scientific Progress
}

Forthcoming in Journal for General Philosophy of Science

Moti Mizrahi, St. John's University

Wesley Buckwalter, University of Waterloo

Abstract: Alexander Bird and Darrell Rowbottom have argued for two competing accounts of the concept of scientific progress. For Bird, progress consists in the accumulation of scientific knowledge. For Rowbottom, progress consists in the accumulation of true scientific beliefs. Both appeal to intuitions elicited by thought experiments in support of their views, and it seems fair to say that the debate has reached an impasse. In an attempt to avoid this stalemate, we conduct a systematic study of the factors that underlie judgments about scientific progress. Our results suggest that (internal) justification plays an important role in intuitive judgments about progress, questioning the intuitive support for the claim that the concept of scientific progress is best explained in terms of the accumulation of true scientific belief.

Keywords: concept of progress; aim of science; justification; scientific knowledge; scientific progress; true belief

\section{Introduction}

The idea that the concept of scientific progress tracks the growth of scientific knowledge looms large in the history of science. It can be traced as far back as Francis Bacon (16206/2000), whose Instauratio magna frontispiece declares: “Multi pertransibunt et augebitur scientia," the Hebrew passage in Daniel 12:4 that reads, "Many shall wander, 
and knowledge shall increase." Three centuries later, Sarton (1936, p. 3-4) expresses a similar sentiment when he says, "The acquisition and systematization of positive knowledge is the only human activity which is truly cumulative and progressive." So it is surprising that despite this tradition, few contemporary philosophers of science directly associate scientific progress with knowledge. As Kitcher (2002, p. 385) observes:

Almost everybody seems to agree that the sciences constitute the richest and most extensive body of human knowledge, and scientists routinely talk of 'what we now know'. Within the philosophy of science, however, there is little explicit discussion of scientific knowledge.

One contemporary exception to the trend noted by Kitcher is the work of Alexander Bird. According to Bird, the answer to the question "What is scientific progress?" closely adheres to the spirit of traditional epistemic accounts. As Bird writes (2007, p. 64):

Science (or some particular scientific field or theory) makes progress precisely when it shows the accumulation of scientific knowledge; an episode in science is progressive when at the end of the episode there is more knowledge than at the beginning.

However, this seemingly anodyne restatement of the historical views mentioned above has recently inspired a vibrant debate. Specifically, this epistemic approach has been heavily criticized by Darrell Rowbottom (2008; 2010). Pace Bird, Rowbottom argues that it is the accumulation of only true scientific belief, rather than knowledge, which is central to the concept of scientific progress. In other words, the concept of scientific progress that we tacitly hold does not require one's scientific beliefs to be justified in order to count as progress. 
One of the main pieces of evidence Rowbottom uses to support this claim comes from intuitions elicited by thought experiments. Theses intuitions, reported by Rowbottom, suggest that intuitive judgments about whether or not scientific progress is achieved are not sensitive to whether or not a scientific belief is justified. Bird's arguments in support of the epistemic account of scientific progress also draw on intuitions elicited by thought experiments. Their appeals to intuitions elicited by thought experiments suggest that both Bird and Rowbottom assume that intuitive judgments about scientific progress are good evidence for understanding the concept of scientific progress. If this is correct, then employing the tools of experimental philosophy to isolate the precise factors present in intuitive judgments might also help us to better understand the concept of scientific progress.

This is exactly what we set out to do in this paper. We present an experimental study to test competing theories of the concept of scientific progress advanced by Bird and Rowbottom by detecting those factors said to make a difference in intuitive judgments. The results of our study suggest — consistent with the epistemic view - that justification is an important part of the ordinary concept of scientific progress. To be clear, we do not attempt to advocate any particular role that justification, or any other of the factors we will discuss, play in the actual practices of the natural sciences. Yet, we do think we provide strong evidence that intuitive judgments about scientific progress are highly sensitive to the justification of true scientific beliefs.

Here is how we plan to proceed. In Section 2, we present the arguments for conceptions of scientific progress found in the works of Bird and Rowbottom, and display some of their assumptions about intuitions in the thought experiments they 
consider. In Section 3, we present the results of our experiment designed to independently manipulate each of the factors discussed in this debate. We conclude in Sections 4 and 5 with a discussion of how these empirical results might serve to reshape the debate about the concept of scientific progress.

\section{The Debate}

In the philosophical literature, philosophers of science have typically been concerned with the following question: what does it mean for one to make scientific progress? Their main project is not to speculate about the practices and methods that lead to actual scientific progress, but rather to pinpoint the conditions by which the concept of progress is characterized. When considering these conditions, Bird (2008, p. 279) distinguishes three promising candidate approaches: the epistemic, semantic, and functional-internalist accounts of the concept of scientific progress.

(E) An episode constitutes scientific progress precisely when it shows the accumulation of scientific knowledge. ${ }^{1}$

(S) An episode constitutes scientific progress precisely when it either (a) shows the accumulation of true scientific belief, or (b) shows increasing approximation to true scientific belief. ${ }^{2}$

\footnotetext{
${ }^{1}$ Though this is the view that Bird defends, it is important to note that knowledge is not taken here to be justified true belief. Instead, Bird thinks that his arguments about scientific progress support Williamson's $(1997 ; 2000)$ view that knowledge is a foundational concept in epistemology and that it does not have an analysis.

${ }^{2}$ Proponents of the semantic approach (S) include Popper (1979) and Niiniluoto (1987).
} 
(FI) An episode shows scientific progress precisely when it achieves a specific goal of science, where that goal is such that scientists can determine its achievement at that time (e.g., solving scientific puzzles). ${ }^{3}$

To the best of our knowledge, (FI) is far less popular among philosophers of science than (S). So it is important to note why (FI) might seem like an attractive view of scientific progress. For Kuhn, the motivation for (FI) comes from his argument from the transcendence of truth. In the Postscript to the second edition of The Structure of Scientific Revolutions, Kuhn (1996, p. 206-207) argues that a correspondence conception of truth leads to skepticism about truth. His argument seems to run as follows: On the correspondence theory of truth, the truth of statement $S$ is a matter of its matching the fact $F$. If the truth of $S$ is a matter of its matching $F$, then knowing that $S$ is true is knowing that $S$ and $F$ match. Knowing that $S$ and $F$ match requires considering $S$ and $F$ independently and then realizing that they match. However, where $S$ is a scientific theory $T$, access to $F$ is always mediated by theories, such as $T$. Since we do not have unmediated access to $F$, i.e., we cannot consider $F$ independently of $T$, we cannot know that $T$ is true.

Now, if theoretical truth is indeed as transcendent as Kuhn argues, then it is understandable how one might think that scientific progress should be understood in terms of something other than theoretical truth, given that theoretical truth is unattainable. In other words, Kuhn is not a skeptic about scientific progress but he is a skeptic about theoretical truth. So he construes progress in terms of an aim that he deems attainable,

\footnotetext{
${ }^{3}$ Proponents of functional-internalist approach (FI) include Kuhn (1996) and Laudan (1977).
} 
namely, puzzle solutions, rather than an aim that he deems unattainable, namely, theoretical truth.

For Laudan, the motivation for (FI) comes from the pessimistic induction. Putting aside the enormous literature that this argument has generated, the basic idea of the pessimistic induction is the following:

The history of science is a graveyard of theories that were empirically successful for a time, but are now known to be false, and of theoretical entities - the crystalline spheres, phlogiston, caloric, the ether and their ilk - that we now know do not exist. Science does not have a good track record for truth, and this provides the basis for a simple empirical generalization. Put crudely, all past theories have turned out to be false, therefore it is probable that all present and future theories will be false as well. That is the pessimistic induction (Lipton 2005, p. 1265). Roughly speaking, then, the argument begins by recalling that many scientific theories were once successful (in terms of their explanatory and predictive power). However, most of these past theories are now considered strictly false. Therefore, the pessimist concludes, current successful theories are probably false as well (Cf. Mizrahi 2013a). Like Kuhn, Laudan is not a skeptic about scientific progress but he is a skeptic about theoretical truth. So, like Kuhn, Laudan construes progress in terms of an aim that he deems attainable, namely, puzzle solutions, rather than an aim that he deems unattainable, namely, theoretical truth.

Bird's (2007, p. 65) aim is to defend (E). Bird considers a number of thought experiments designed to show that "our intuitions about whether there is progress show that progress matches changes in knowledge, but not changes in truth or in problem- 
solving" (emphasis added). For example, here is one of Bird's thought experiments concerning (E) and (S):

Imagine a scientific community that has formed its beliefs using some very weak or even irrational method $\mathrm{M}$, such as astrology. But by fluke this sequence of beliefs is a sequence of true beliefs. These true beliefs are believed solely because they are generated by M and they do not have independent confirmation. Now imagine that at time $t$ an Archimedes-like scientist in this society realises and comes to know that $\mathrm{M}$ is weak. This scientist persuades (using different, reliable methods) her colleagues that $\mathrm{M}$ is unreliable. This may be that society's first piece of scientific knowledge. The scientific community now rejects its earlier beliefs as unsound, realising that they were formed solely on the basis of a poor method (Bird 2007, p. 66).

In this scenario, a scientific community has accidentally formed true beliefs on the basis of an inadequate method, or a method that leads to the formation of beliefs without sufficient epistemic support. ${ }^{4}$ Once the scientist realizes that the method is epistemically inadequate, the scientific community rejects its previously held beliefs. But did the scientific community make progress, and when? According to (S), a sequence of lucky guesses or irrational beliefs with increasing verisimilitude counts as progress. So on (S), the scientific community was making progress, and then regressed after it was discovered

\footnotetext{
${ }^{4}$ There are many different ways in which the belief formation method may be inadequate. For instance, Bird also considers the real-world example of René Blondlot's (apparently entirely spurious and irrational) belief in entities called N-rays. Had these entities actually existed, then on (S), but not (E), this would be a case of scientific progress because his belief would have been true.
} 
that the method is irrational. However, according to (E), knowledge is essential to progress. On (E), this community made progress only after the discovery that the method is inadequate.

As Bird (2007, p. 65) writes, (S) "yields a verdict about progress in certain kinds of cases [i.e., cases of beliefs with insufficient epistemic support] that is at odds with our intuitions." Instead, our intuitions, according to Bird (2007, p. 65) "imply that epistemic characteristics are essential to progress." If one shares Bird's intuition, then this seems to show that it is not an increase in true beliefs that is sufficient for scientific progress, but rather the accumulation of scientific knowledge.

Similarly, Bird also appeals to intuitions when arguing against (FI). Working with two different problem-solving views about science — those of Kuhn and Laudan-Bird attempts to elicit the intuition that increases in puzzle-solutions, without increases in true belief, are not instances of genuine scientific progress. ${ }^{5}$ For example, Bird considers the case of Nicole d'Oresme:

Nicole d'Oresme and his contemporaries believed that hot goat's blood would split diamonds (Oresme 1968; example cited in Laudan 1977, p. 16). Now, according to Kuhn, a puzzle is solved when a proposed solution is sufficiently similar to a relevant paradigmatic puzzle-solution. The key factor in choosing a new paradigm is its ability to preserve as much as possible the problem-solving power of its predecessor while permitting the solution or dissolution of as many outstanding anomalies as possible. On Kuhn's view, then, if Nicole d'Oresme can "solve the

\footnotetext{
${ }^{5}$ Importantly, neither Kuhn nor Laudan think that science requires knowledge; Laudan due to the pessimistic induction, and Kuhn due to his critiques of truth and verisimilitude.
} 
problem" of how to split diamonds using hot goat's blood by coming up with a solution that is sufficiently similar to an appropriate paradigm, then he has made progress. Now, suppose that someone shows that Oresme's solution cannot work. On Kuhn's view, we had a solution before, now we have none; that is regress. Intuitively, however, and on $(\mathrm{E})$, that person contributed to progress in a small way, by giving us knowledge that something previously thought true is actually false. Bird's intuition is that Oresme's false solution to a false problem is not progress, but the knowledge that his false solution is indeed false is some small contribution to progress. ${ }^{6}$

According to Laudan, a problem $P$ is solved by theory $T$ when one can deduce a statement of $P$ from $T$ (where $T$ doesn't have to be true or $P$ may not even exist). ${ }^{7}$ On Laudan's view, then, if Nicole d'Oresme can "solve the problem" of how to split diamonds using hot goat's blood by coming up with a theory from which he can deduce the splitting of diamonds by hot goat's blood, then he has made progress. Now, suppose that someone shows that Oresme's solution cannot work. On Laudan's view, since we no

\footnotetext{
${ }^{6}$ For Kuhn (1996), exemplars, rather than the application of rules, play a dominant role in scientific cognition. A puzzle-solution may be accepted or not, according to Kuhn, depending on its similarity to paradigmatic puzzle-solutions. For Kuhn, determining the similarities between puzzle-solutions is not a matter of following or applying rules. See Bird (2000).

${ }^{7}$ According to Laudan (1981, p. 148), "the problem-solving approach allows a problem solution to be credited to a theory, independent of how well established the theory is, just so long as the theory stands in a certain formal relation to (a statement of) the problem." In that respect, Laudan's account is like Hempel's Deductive-Nomological model of explanation (at least superficially) to the extent that, according to the DN model, "the explanandum [i.e., a statement describing the phenomenon to be explained] must be a logical consequence of the explanans [i.e., the class of those statements that are adduced to account for the phenomenon]" (Hempel 1965, p. 247-248).
} 
longer have a deduction from $T$ to $P$, that is regress. According to (E), however, discovering that one possible solution is incorrect counts as progress. Again, Bird's intuition is that Oresme's false solution to a false problem is not progress, but the knowledge that it is false does constitute some small contribution to progress.

Bird's intuitions tell him that increases neither in merely true belief nor in problem-solving alone constitute progress. But this is not the last word about "our intuitions." Contrary to Bird, Rowbottom argues against (E) and in support of (S) also on the basis of intuitions elicited by thought experiments. Rowbottom (2010) seeks to refute (E) by providing a counterexample. Since he takes Bird to be committed to the claim that (i) justification is necessary for scientific progress and the claim that (ii) knowledge entails justification, Rowbottom seeks to provide an example of scientific progress without justification. To that end, Rowbottom (2010, p. 242) considers the following thought experiment:

Consider two planets; the inhabitants of the first have no justified scientific beliefs (although they have many true ones), whereas the inhabitants of the second have many justified scientific beliefs and considerable scientific knowledge. But the civilizations on each of these planets appear, on the surface, to be equally as advanced. Each has developed similar technology, has similar societies and institutions, uses similar scientific theories, and so forth. Roughly, we'd say they were at the same stage of technological development as we were at the turn of the twentieth century. Now add that the people on each of the planets began in similarly primitive circumstances and proceeded without any outside interference. In short, neither group had an initial theoretical or technological advantage over 
the other, or acquired one from an external source. Now add that the people on each of the planets began in similarly primitive circumstances and proceeded without any outside interference. In short, neither group had an initial theoretical or technological advantage over the other, or acquired one from an external source.

For Rowbottom, this thought experiment refutes (E), since his intuition is that the people on both planets have each made some kind of progress. For Rowbottom, this shows that progress is possible without justification. Since it is traditionally thought that knowledge requires justification, it follows that progress does not consist in the accumulation of knowledge. As Rowbottom (2010, p. 242) writes:

If it is right to say that such a scenario is metaphysically possible, and if it is correct to say that the people on each planet have made some scientific progress (which I emphasize need not be equal), then the epistemic view of progress is refuted.

So where are we in the dialectic? Here is how we see the state of play. Both Bird and Rowbottom have offered us compelling intuitions elicited by thought experiments in support of their views. It seems fair to say that the debate has reached an impasse. Here is why we think it is fair to say that the debate has reached an impasse. Bird and Rowbottom obviously have incompatible intuitions about the same thought experiments. It seems unlikely that either of them will change his intuitions about these thought experiments. So, since their intuitions about the ordinary concept of scientific progress diverge, and those intuitions are unlikely to change, it seems reasonable to propose a new approach to the question of scientific progress. Accordingly, we propose an empirical 
study of actual intuitions about scientific progress. If it is true, as both Bird and Rowbottom seem to assume, that intuitive judgments elicited by thought experiments can shed light on the ordinary concept of scientific progress, then it would be interesting to find out whether actual intuitions best support (E), (S), or (FI) in experimental conditions with properly controlled variables. We now turn to this experiment.

\section{The Experiment}

Our experiment was designed to test intuitive judgments about putative cases of scientific progress. To figure out whether or not intuitions agree with (E) or (S), we manipulated three variables within the confines of our vignettes relative to these different views about progress. One variable involved the types of goals scientists may have: either technological goals (in these vignettes, we described scientists as "working with electronic circuit boards") or theoretical goals (in these vignettes, we described scientists as "working with equations" and the theory of relativity). The other two variables involved whether or not the discoveries the scientists made in our vignettes were internally justified and/or externally justified (see Appendix).

In order to independently manipulate these three factors, 397 participants were randomly shown one of eight possible different cases in a 2 (goal type) x 2 (internal justification) x 2 (external justification) experimental design. ${ }^{8}$ Here is an example of two

\footnotetext{
${ }^{8}$ Participants, 160 female, aged $19-68, M=36$ years, $S D=11.97$ years. Participants were recruited using Amazon Mechanical Turk as well as through the Yale Experiment Month initiative (http://www.yale.edu/cogsci/XM/Info.html). Participants were tested online using Qualtrics survey software, and compensated $\$ 0.25$ for approximately 2-3 minutes of their time. Participants were located throughout the United States. They filled out a brief demographic survey after testing. Participants reported
} 
of the eight cases administered. Both cases below involve scientists whose goal is technological, but they lack external justification. The vignettes both begin as follows (emphasis added):

A group of scientists at the Institute for Advanced Study has been studying the speed of light. Working with electronic circuit boards, the scientists were trying to find particles that travel faster than light. One day, during an anomalous power surge, the computer program the scientists were using managed to physically accelerate the particles in the circuit boards to speeds faster than that of light. As it turns out, the circuit boards work perfectly, and these faster-than-light particles, called "tachyons," really were being accelerated.

In this case, we take it that the scientists do not have external justification for the belief that the particles in the circuit boards are faster than light because an anomalous power surge is not a reliable belief-forming process. This belief just so happens to be true as a result of an accident, not as a result of any reliable process. On the other hand, in the vignette where the scientists did have external justification for their belief that the particles in the circuit boards are faster than light, we replaced "an anomalous power surge" with "a day of routine calculations," thus suggesting that the computer was working properly, and that the same results would be obtained if the process were to be repeated.

highest level of education (7.6\% high school graduate; $22.2 \%$ some college, no degree; $27 \%$ bachelor's degree; $30.2 \%$ graduate degree). Participants also reported levels of post-secondary training specifically in the natural sciences $(28.2 \%)$, social sciences $(35.9 \%)$, and technology or engineering (16.1\%). We did not detect any differences in intuitions of scientific progress based on these demographic variables. 
The vignette where scientists lacked internal justification proceeded like this (emphasis added):

A group of scientists at the Institute for Advanced Study has been studying the speed of light. Working with electronic circuit boards, the scientists were trying to find particles that travel faster than light. One day, during a day of routine calculations, the computer program the scientists were using managed to physically accelerate the particles in the circuit boards to speeds faster than that of light. As it turns out, the circuit boards work perfectly, and these faster-than-light particles, called "tachyons," really were being accelerated. The scientists reviewed the logs immediately, but they could not figure out how the program performed the acceleration.

In this case, we take it that the scientists do not have internal justification for the belief that the particles in the circuit boards are faster than light because they do not have any access to the grounds for this belief, since they cannot figure out how the computer performed the acceleration. Their belief just so happens to be true but the scientists have no idea why. On the other hand, in the vignette where the scientists did have internal justification for their belief that the particles in the circuit boards are faster than light, we replaced "could not figure out how" with "figured out how," thus suggesting that the scientists have access to the grounds for their belief in tachyons and that they are able to tell how the computer performed the acceleration.

After reading one of these vignettes (see Appendix for the rest), participants were then asked, “On a 7-point scale, 1 meaning 'no progress' and 7 meaning 'enormous progress', how much scientific progress has been made in the story above?" 
We found that people answered very differently between these two different cases. When the scientists were justified internally, participants were more likely to attribute scientific progress $(M=6.00, \mathrm{SD}=1.21)$ than when they lacked any internal justification $(M=4.58, \mathrm{SD}=1.56)$. These results are shown in Figure 1. While this is only two of the eight different combinations of cases given, this tendency was indicative of our general finding. The main result of our study is that internal justification had a large impact on people's intuitive judgments about scientific progress independently of having or lacking external justification, or having different types of scientific goals. ${ }^{9}$ On the other hand, external justification and goal type alone seemed to make no difference on participants' intuitive judgments. These results are shown in Figures 2 and 3.

Finally, there was also an interaction between internal justification and goal type. Interestingly, people's intuitive judgments were slightly more impacted by the degree of internal justification present in the various vignettes in technological cases than in theoretical cases. ${ }^{10}$ Nonetheless, internal justification still seems to be the driving force in people's intuitive judgments.

\footnotetext{
${ }^{9}$ For Theoretical Progress cases: No External/No Internal $(M=4.69, S D=1.67)$; No External/Internal $(M=$ 5.77, $S D=1.38)$; External/No Internal $(M=4.83, S D=1.53)$; External/Internal $(M=5.51, S D=1.41)$. For Technological Progress cases: No External/No Internal $(M=4.58, S D=1.56)$; No External/Internal $(M=$ 6.00, $S D=1.21)$; External/No Internal $(M=4.42, S D=1.60)$; External/Internal $(M=6.05, S D=1.09)$. ${ }^{10}$ A multiple-way between-subjects analysis of variance was conducted to evaluate the effect of internal justification, external justification, and scientific goal on participants' judgments about scientific progress. We found a main effect for internal justification $F(1,389)=67.34, p<0.01$, but were not able to detect a main effect for external justification $F(1,389)=0.15, p=0.699$. We also detected an interaction effect between internal justification and scientific goal, $F(1,389)=4.86, p<0.05$.
} 


\section{The Ordinary Concept of Scientific Progress}

As we have seen, both Bird and Rowbottom appeal to intuitions elicited by thought experiments in support of their views about scientific progress. Since Bird's and Rowbottom's intuitions about the ordinary concept of scientific progress diverge, and it is unlikely that their intuitions will change, it seems fair to say that the debate has reached an impasse and that a new approach might be fruitful. We think that our study might offer a way out of this stalemate. Contrary to (S), our findings point to the important role that justification plays in intuitive judgments about scientific progress. Similarly, while the degree to which (internal) justification mattered was influenced partly by the type of scientific goal, our results indicate that without the presence of scientific knowledge, (FI) will not accurately account for intuitive judgments about progress. Conversely, our results seem to indicate that people's ordinary conceptions of scientific progress may conform most closely with (E), according to which justification is an important part of what constitutes scientific progress. Interestingly, however, whereas Bird prefers to think of justification along externalist lines, it seems that intuitive judgments about progress are highly sensitive to internal, rather than external, justification.

We think that our results support the following argument, which is intended neither as a refutation of $(\mathrm{S})$ nor as a proof of $(\mathrm{E})$ :

1. If intuitive judgments elicited by thought experiments can shed light on the ordinary concept of scientific progress, then a systematic survey of intuitive judgments can help us get a better understanding of the ordinary concept of scientific progress. 
2. If a systematic survey of intuitive judgments can help us get a better understanding of the ordinary concept of scientific progress, then such a survey shows that intuitive judgments about the ordinary concept of scientific progress are highly sensitive to (internal) justification.

3. Therefore, if intuitive judgments elicited by thought experiments can shed light on the ordinary concept of scientific progress, then intuitive judgments about the ordinary concept of scientific progress are highly sensitive to (internal) justification.

To be clear, we need not be committed to the claim that intuitive judgments elicited by thought experiments can shed light on the ordinary concept of scientific progress. However, Bird and Rowbottom are committed to this claim, since they appeal to intuitions in support of (E) and (S) respectively. In other words, Bird and Rowbottom are debating the necessary and sufficient conditions of the ordinary concept of scientific progress. In the course of their debate, they appeal to intuitions elicited by thought experiments as evidence for their respective analyses of the ordinary concept of scientific progress. Since they appeal to intuitions, then, they must think that intuitions can tell us what the necessary and sufficient conditions of an ordinary concept are. However, an appeal to intuition would be rather weak if the intuition is idiosyncratic. Since our results show that intuitions mostly align with (E), rather than (S), and given the assumption that intuitions can tell us about the necessary and sufficient conditions of an ordinary concept (to which Bird and Rowbottom seem to be committed), it follows that justification is a necessary condition as far as the ordinary concept of scientific progress is concerned. 
Of course, we do not think that (S) or (FI) are refuted on the basis of just this one experiment. The fact that justification is an important part of the ordinary concept of scientific progress does not mean that (S) is false, if (S) only requires the existence of one case in which justification is not necessary. Such cases could still be out there.

Furthermore, it is always difficult to interpret Likert scales (especially those anchored with non-standard or complicated terms like scientific progress). The experiment presented in this paper is no exception. For instance, it might be thought that given the relatively high ratings of participants in non-justification conditions (about the midpoint of our seven-item scale in those cases), that this demonstrates a situation in which people think that perhaps at least "some" progress is possible without justification.

We think that future research will be instrumental in answering these questions. Nevertheless, we do think that our findings present a challenge for proponents of (S). The challenge is about the explanatory power of (S). Suppose that instead of just proposing a broad necessary condition, you wanted to give a conceptual analysis of the ordinary concept of scientific progress that was informative, or more specifically, mapped applications of that ordinary concept. Our data suggest that (S) may lack the conceptual resources that could explain intuitive judgments about scientific progress. Since intuitive judgments about scientific progress are highly sensitive to (internal) justification, and since (S) is principally the view that justification is not a necessary condition for scientific progress, it is difficult to see how (S) could offer a descriptively accurate view of the ordinary concept of scientific progress that people actually use. 


\section{Objections}

There seem to be at least three moves that proponents of (S) could make in response to the aforementioned challenge.

(1) Proponents of (S) could insist that not all intuitions are born equal. That is, they might argue that only the intuitions of formally trained philosophers or scientists, rather than ordinary people, should count as evidence. Or alternatively, they might argue that the intuitive judgments of non-experts do count as evidence for the ordinary concept of scientific progress, but that the ordinary concept of progress is somehow philosophically uninteresting.

(2) Proponents of (S) might insist that they do not care about explaining intuitive judgments about scientific progress. They might argue that (S) is a strictly normative account insofar as it purports to tell us how we ought to apply the ordinary concept of scientific progress, rather than how we actually apply it.

(3) Since in the cases with internal justification it might seem as if the scientists simply have more true beliefs, compared with the cases in which the scientists do not have internal justification, proponents of (S) might insist that the main effect for internal justification in our experiment could be explained by saying that the cases with internal justification are simply cases with more true beliefs than the cases without internal justification.

Regarding (1), there is an ongoing debate at the intersection of philosophy and psychology regarding something called the "expertise defense." In short, the expertise defense states that roughly, only the intuitions of experts, or formally trained philosophers, should be used as evidence in philosophical argumentation. We do not 
think this is the place to rehearse this debate. But we think it is important to note that various formulations of this defense are currently very much in dispute (see, e.g., Weinberg et al. 2010; Schwitzgebel and Cushman 2012; Tobia et al 2013). Also, we think that in this particular instance, the expertise defense is complicated by the fact that the intuitions in question are about progress in another discipline - that of the natural sciences. If proponents of $(\mathrm{S})$ were to make this move, then it seems that they would have to say who the experts are in this debate, and why their intuitions in controlled thought experiments count as better evidence for the concept of progress than others. And it is far from clear whether philosophers are experts about scientific progress. So, if proponents of (S) wish to appeal to the expertise defense, they have a lot of explaining to do. They have to say what makes philosophers experts on scientific progress. And they have to say how the intuitive judgments of philosophers are different from and better than the intuitive judgments of those who are not philosophers of science.

We think that these are interesting empirical questions. And of course, the best way to answer them is to conduct more empirical studies looking at the intuitions of formally trained philosophers, scientists, and generally "scientifically well-informed" persons. In the meantime however, we have some independent reasons for expecting such a study to align with our current findings. A survey of the history of science and the practices of scientists reveals that scientists themselves talk about progress in terms of knowledge and evaluate progress relative to epistemic criteria (Mizrahi 2013b). It is also worth mentioning here that our experimental sample above-while not displaying any significant differences for several measures of exposure to scientific training-did 
include participants with diverse backgrounds in the sciences, ranging from a few college courses to advanced doctoral degrees (see footnote 8).

As for (2), it is important to remember that the explanandum at issue in this debate concerns the ordinary concept of scientific progress. We need not take any stance on whether or not the intuitions that philosophers or non-philosophers have in response to the thought experiments we give bear any sort of metaphysical or normative relationship to progress across the sciences. In fact, we are quite skeptical that intuitions in thought experiments are very good evidence for these latter questions, in lieu of simply studying the practices and techniques of scientists. But our project has been to try and analyze the concept of progress that people tacitly hold. And for this, we look to intuitive judgments, as Bird and Rowbottom do. Now, if proponents of (S) were to insist that (S) is not intended to explain intuitive judgments about scientific progress, then it seems that they would undermine the support for their theory. For recall that support for (S) is supposed to come from intuitions elicited by thought experiments. If these intuitions count as evidence for (S), then it seems reasonable to think that (S) should be able to account for these intuitions. The relation here seems to be symmetrical. For example, the fact that Venus exhibits phases counts as evidence for the heliocentric model. And the heliocentric model can explain why Venus exhibits phases. If the heliocentric model were unable to explain why Venus exhibits phases, then it is difficult to see how the phases of Venus could count as evidence for the heliocentric model. Similarly, if (S) is unable to explain why intuitive judgments about scientific progress are highly sensitive to (internal) justification, then it is difficult to see how intuitive judgments about scientific progress could count as evidence for (S). Since proponents of (S) appeal to intuitions elicited by 
thought experiments as support for $(\mathrm{S})$, it seems that their theory should be able to account for these intuitive judgments. That is precisely why our findings challenge the explanatory power of $(\mathrm{S})$.

As for (3), if proponents of (S) were to insist that the main effect for internal justification can be explained by the addition of true beliefs, then it seems that this would be a rather unsatisfactory explanation. For, in some sense, there are clearly more true beliefs in the cases where the scientists have internal justification, for internal justifications are also true beliefs (which is not to say that true beliefs are internal justifications). For example, my true belief that my watch tells the right time could serve as (internal) justification for my true belief that it is 5:25 PM. Now, recall that (E) is the view that the accumulation of scientific knowledge constitutes scientific progress. That means that truth alone is not sufficient for progress. So proponents of (E) do not deny that truth is necessary for progress. Rather, they argue that, in addition to truth, justification is also necessary for progress. But when one adds internal justification, it seems that one is clearly adding true beliefs as well, given that internal justification is supposed to be the sort of justification to which one has some sort of access. ${ }^{11}$

In that respect, it is also worth making the following clarification. Some might think that our results actually support (S), rather than (E), since most subjects responded that some progress has been made, which is all that is required for $(\mathrm{S})$ to be true.

\footnotetext{
${ }^{11}$ In that respect, we should add the following caveat. If one interprets our results as support for (E), then one must be willing to pay a certain price. The price, it seems, is that one might have to forego externalism about justification, at least as far as scientific knowledge is concerned. We acknowledge that some might reasonably think that this is a heavy price to pay.
} 
However, this interpretation of our results is incomplete, and hence unsatisfactory, for the following reason. If (S) were true, we would expect the following to be true:

(S1) Most subjects would respond that some progress has been made even when scientists lack justification (whether internal or external).

(S2) Subjects' responses would track only true belief (without justification). Although it is questionable whether or not $(\mathrm{S} 1)$ is borne out by our experimental results, it is clear that (S2) is not. Our results show that subjects' responses track justification, not merely true belief, insofar as subjects are more likely to say that progress has been made when scientists are justified, and hence know, than when scientists are not justified, and hence don't know.

Similarly, if (E) were true, we would expect the following to be true:

(E1) Most subjects would respond that no progress has been made when scientists lack justification (whether internal or external).

(E2) Subjects' responses would track justification, not merely true belief. Although it is questionable whether or not (E1) is borne out by our experimental results, it is clear that (E2) is. Our results show that subjects' responses indeed track justification, not merely true belief, insofar as subjects are more likely to judge that progress has been made when scientists are justified than when they are not justified. For these reasons, we do not claim to have proved (E). Nor do we claim to have refuted (S). Rather, we claim that our results challenge the explanatory power of $(\mathrm{S})$. 


\section{Conclusion}

Thinking of scientific progress in general terms as the advancement of scientific knowledge has had a rich historical tradition in the philosophy of science. However, the recent debate between Bird and Rowbottom has questioned whether our contemporary intuitions really do accord with the epistemic, functional-internalist or semantic characterizations of the ordinary concept of scientific progress. In this paper, our aim has been to present empirical evidence that supports the claim that justification is an important part of the ordinary concept of scientific progress.

Thus we think a natural way to proceed in studying the concept of progress is to continue this empirical programme in the philosophy of science by focusing specifically on the role of justification in scientific discovery. Specifically, more experimental work should be done looking at the question of which form of internalism—or whether the standard internalist characterization of internalism over various externalist characterizations as suggested above — best tracks ordinary judgments. As we also noted above, more work needs to be done comparing the ordinary concept of progress with the concept or concepts tacitly held by scientists of different specialities (though see also Mizrahi 2013b). Lastly we also think it would be interesting to compare intuitional judgments about the role of justification with behavioural data about the practices and techniques actual scientists advocate in the contexts of discovery. We suspect that observational data regarding these practices and techniques will further support the role of justification in the concept of scientific progress over the accumulation of true scientific beliefs. 
To reiterate, however, we do not claim to have refuted (S). We do not present evidence for the claim that people think that scientific progress is completely impossible without scientific knowledge. Perhaps this goes to show that a philosopher's work toward advocating a particular necessary condition for the successful deployment of an ordinary concept is never done. Yet, as far as understanding the ordinary concept of scientific progress is concerned, we think that progress can be made by looking at the factors that play important roles in intuitive judgments. While more research is needed to map the extent and limits to which justification is central to the ordinary concept of scientific progress, our data suggest that any correct analysis of the ordinary concept of scientific progress - be it semantic, epistemic, or functional-internalist - should be adapted to account for this role.

\section{Acknowledgments}

This study was included in Experiment Month, which was sponsored by the American Philosophical Association (APA) and coordinated by Yale University's Cognitive Science. The results were presented at the APA Eastern Division 108th Annual Meeting in Washington DC, December 27-30, 2011. We would like to thank Joshua Knobe, Mark Phelan, and Darrell Rowbottom for helpful discussion. We are also grateful to two anonymous reviewers for the Journal for General Philosophy of Science for helpful comments on an earlier draft. 


\section{References}

Bacon, F. 1620-6/2000. The Instauratio Magna: Last Writings. In The Oxford Francis Bacon XIII. Oxford: Clarendon Press.

Bird, A. 2000. Thomas Kuhn. Princeton, NJ: Princeton University Press.

Bird, A. 2007. What Is Scientific Progress? Nous 41:64-89.

Bird, A. 2008. Scientific Progress as Accumulation of Knowledge: A Reply to Rowbottom. Studies in the History and Philosophy of Science 39:279-281.

Hempel, C. 1965. Aspects of Scientific Explanation and Other Essays in the Philosophy of Science. New York: Free Press.

Kitcher, P. 2002. "Scientific Knowledge.” Pp. 385-407 in The Oxford Handbook of Epistemology. Edited by P. K. Moser. New York: Oxford University Press.

Kuhn, T. S. (1962) 1996. The Structure of Scientific Revolutions. Chicago: The University of Chicago Press.

Laudan, L. 1977. Progress and its Problems: Toward a Theory of Scientific Growth. Berkeley: University of California Press. 
Laudan, L. 1981. A Problem-Solving Approach to Scientific Progress. Pp. 144-155 in Scientific Revolutions. Edited by I. Hacking. New York: Oxford University Press.

Lipton, P. 2005. The Truth about Science. Philosophical Transactions of the Royal Society B 360:1259-1269.

Mizrahi, M. 2013a. The Pessimistic Induction: A Bad Argument Gone Too Far. Synthese 190:3209-3226.

Mizrahi, M. 2013b. What is Scientific Progress? Lessons from Scientific Practice. Journal for General Philosophy of Science. DOI 10.1007/s10838-013-9229-1.

Niiniluoto, I. 1987. Truthlikeness. Boston, MA: Kluwer Academic Publishers.

Oresme, N. (ca. 1350) 1968. Nicole Oresme and the medieval geometry of qualities and motions: a treatise on the uniformity and difformity of intensities known as Tractatus de configurationibus qualitatum et motuum. Publications in Medieval Science. Vol. 12. Edited by Marshall Clagett. University of Wisconsin Press.

Popper, K. 1979. Objective Knowledge: An Evolutionary Approach. Oxford: Clarendon Press. 
Tobia, K., Buckwalter, W. \& Stich, S. 2013. Moral Intuitions: Are Philosophers Experts? Philosophical Psychology 26:629-638.

Rowbottom, D. 2008. N-Rays and the Semantic View of Scientific Progress. Studies in the History and Philosophy of Science 39:277-278.

Rowbottom, D. 2010. What Scientific Progress Is Not: Against Bird's Epistemic View. International Studies in the Philosophy of Science 24:241-255.

Sarton, G. 1936. The Study of the History of Science. Harvard: Harvard University Press.

Schwitzgebel, E. and Cushman, F. 2012. Expertise in Moral Reasoning? Order Effect on Moral Judgment in Professional Philosophers and Non-philosophers. Mind and Language 27:135-153.

Weinberg, J. Gonnerman, C., Buckner, C. and Alexander, J. 2010. Are Philosophers Expert Intuiters? Philosophical Psychology 23:331-355.

Williamson, T. 1997. Knowledge as Evidence. Mind 106:717-741.

Williamson, T. 2000. Knowledge and Its Limits. New York: Oxford University Press. 


\section{Figures}

Figure 1. Mean intuitive judgements of Scientific Progress for technological cases lacking external justificaiton.

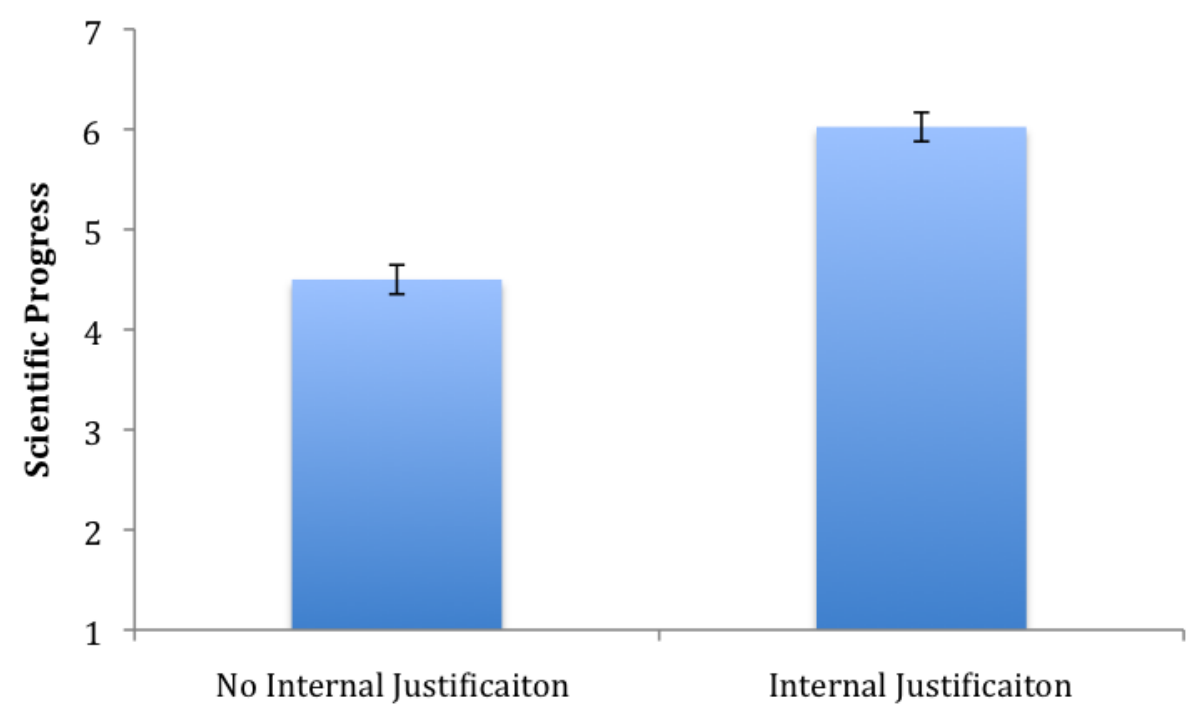

Figure 2. Mean intuitive judgements of Scientific Progress for technological cases, grouped by Internal and External Justificaiton. All scales ran 1-7.

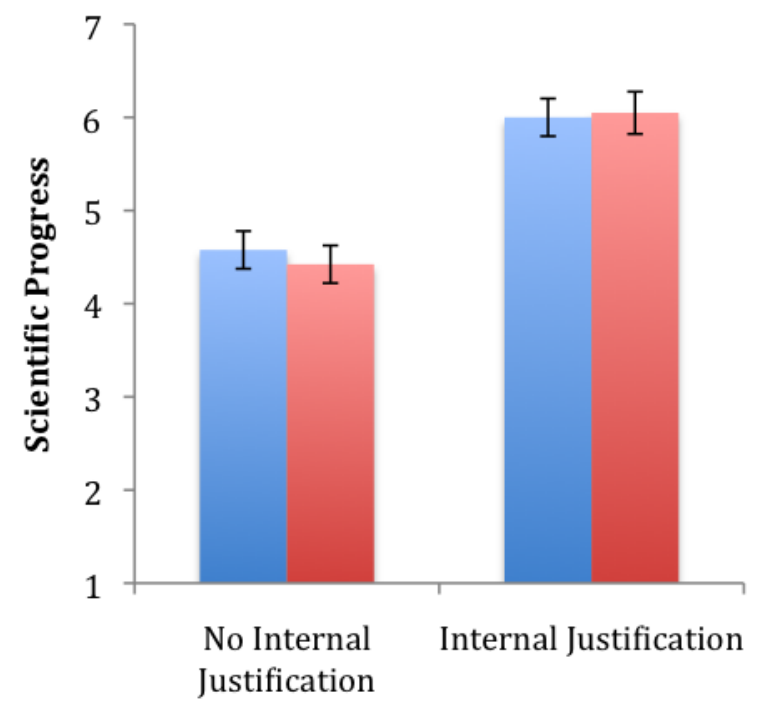

No External Justification

External Justification 
Figure 3. Mean intuitive judgements of Scientific Progress for theoretical cases, grouped by Internal and External Justificaiton.

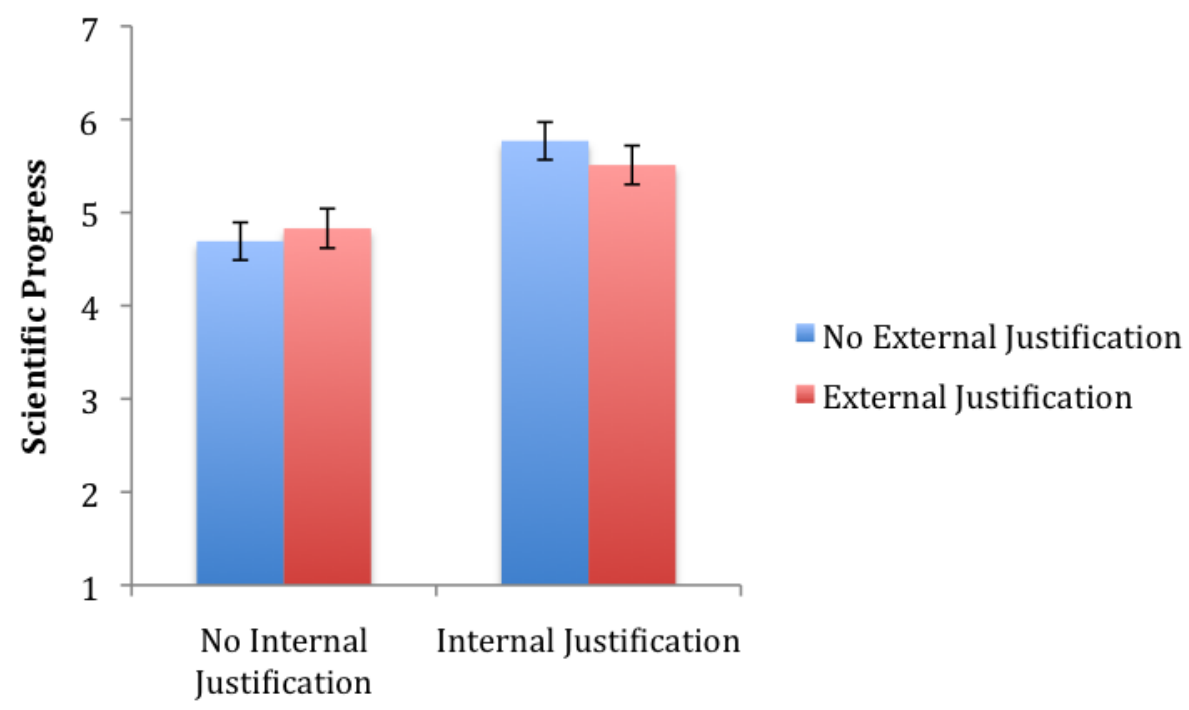




\section{Appendix}

\begin{tabular}{|l|l|l|l|l|}
\hline & \multicolumn{2}{|l|}{ Theoretical Goal } & \multicolumn{2}{l|}{ Technological Goal } \\
\hline & $\begin{array}{l}\text { External } \\
\text { Justification }\end{array}$ & $\begin{array}{l}\text { No } \\
\text { External }\end{array}$ & $\begin{array}{l}\text { External } \\
\text { Justification }\end{array}$ & $\begin{array}{l}\text { No } \\
\text { External }\end{array}$ \\
\hline $\begin{array}{l}\text { Internal } \\
\text { justification }\end{array}$ & 1 & 2 & 5 & 6 \\
\hline No Internal & 3 & 4 & 7 & 8 \\
\hline
\end{tabular}

(1) A group of scientists at the Institute for Advanced Study has been studying the speed of light. Working with the Theory of Relativity, the scientists were trying to find particles that travel faster than light. One day, during a day of routine calculations, the computer program the scientists were using managed to mathematically demonstrate the existence of these faster-than-light particles with an equation. As it turns out, this equation works perfectly, and these particles, called "tachyons," really do exist. The scientists reviewed the logs immediately, and they figured out how the program performed the demonstration.

(2) A group of scientists at the Institute for Advanced Study has been studying the speed of light. Working with the Theory of Relativity, the scientists were trying to find particles that travel faster than light. One day, during an anomalous power surge, the computer program the scientists were using managed to mathematically demonstrate the existence of these faster-than-light particles with an equation. As it turns out, this equation works perfectly, and these particles, called "tachyons," really do exist. The scientists reviewed the logs immediately, and they figured out how the program performed the demonstration.

(3) A group of scientists at the Institute for Advanced Study has been studying the speed of light. Working with the Theory of Relativity, the scientists were trying to find particles 
that travel faster than light. One day, during a day of routine calculations, the computer program the scientists were using managed to mathematically demonstrate the existence of these faster-than-light particles with an equation. As it turns out, this equation works perfectly, and these particles, called "tachyons," really do exist. The scientists reviewed the logs immediately, but they could not figure out how the program performed the demonstration.

(4) A group of scientists at the Institute for Advanced Study has been studying the speed of light. Working with the Theory of Relativity, the scientists were trying to find particles that travel faster than light. One day, during an anomalous power surge, the computer program the scientists were using managed to mathematically demonstrate the existence of these faster-than-light particles with an equation. As it turns out, this equation works perfectly, and these particles, called "tachyons," really do exist. The scientists reviewed the logs immediately, but they could not figure out how the program performed the demonstration.

(5) A group of scientists at the Institute for Advanced Study has been studying the speed of light. Working with electronic circuit boards, the scientists were trying to find particles that travel faster than light. One day, during a day of routine calculations, the computer program the scientists were using managed to physically accelerate the particles in the circuit boards to speeds faster than that of light. As it turns out, the circuit boards work perfectly, and these faster-than-light particles, called "tachyons," really were being accelerated. The scientists reviewed the logs immediately, and they figured out how the program performed the acceleration. 
(6) A group of scientists at the Institute for Advanced Study has been studying the speed of light. Working with electronic circuit boards, the scientists were trying to find particles that travel faster than light. One day, during an anomalous power surge, the computer program the scientists were using managed to physically accelerate the particles in the circuit boards to speeds faster than that of light. As it turns out, the circuit boards work perfectly, and these faster-than-light particles, called "tachyons," really were being accelerated. The scientists reviewed the logs immediately, and they figured out how the program performed the acceleration.

(7) A group of scientists at the Institute for Advanced Study has been studying the speed of light. Working with electronic circuit boards, the scientists were trying to find particles that travel faster than light. One day, during a day of routine calculations, the computer program the scientists were using managed to physically accelerate the particles in the circuit boards to speeds faster than that of light. As it turns out, the circuit boards work perfectly, and these faster-than-light particles, called "tachyons," really were being accelerated. The scientists reviewed the logs immediately, but they could not figure out how the program performed the acceleration.

(8) A group of scientists at the Institute for Advanced Study has been studying the speed of light. Working with electronic circuit boards, the scientists were trying to find particles that travel faster than light. One day, during an anomalous power surge, the computer program the scientists were using managed to physically accelerate the particles in the circuit boards to speeds faster than that of light. As it turns out, the circuit boards work perfectly, and these faster-than-light particles, called "tachyons," really were being 
accelerated. The scientists reviewed the logs immediately, but they could not figure out how the program performed the acceleration. 